Article

\title{
Human Milk Oligosaccharide, Phospholipid, and Ganglioside Concentrations in Breast Milk from United Arab Emirates Mothers: Results from the MISC Cohort
}

\author{
Paul McJarrow ${ }^{1, *,+} \mathbb{D}$, Hadia Radwan $\left.{ }^{2,+}{ }^{(}\right)$, Lin Ma ${ }^{1}$, Alastair K.H. MacGibbon ${ }^{1}$, \\ Mona Hashim 2,3, Hayder Hasan 2®D, Reyad Shaker Obaid ${ }^{2}$, Farah Naja ${ }^{4}$, \\ Hamid Jan Jan Mohamed ${ }^{3}$, Hessa Al Ghazal ${ }^{5}$ and Bertram Y. Fong ${ }^{1}$ \\ 1 Fonterra Research and Development Centre, Dairy Farm Road, Private Bag 11029, Palmerston North 4442, \\ New Zealand; kevin.ma@fonterra.com (L.M.); alastair.macgibbon@fonterra.com (A.K.H.M.); \\ bertram.fong@fonterra.com (B.Y.F.) \\ 2 Department of Clinical Nutrition and Dietetics, College of Health Sciences, Research Institute of Medical and \\ Health Sciences (RIMHS), University of Sharjah, Sharjah 27272, UAE; hradwan@sharjah.ac.ae (H.R.); \\ mhashim@sharjah.ac.ae (M.H.); haidarah@sharjah.ac.ae (H.H.); robaid@sharjah.ac.ae (R.S.O.) \\ 3 School of Health Sciences, Universiti Sains Malaysia, Kubang Kerian 16150, Malaysia; hamidjan@usm.my \\ 4 Department of Nutrition and Food Sciences, American University of Beirut, Beirut 1107 2020, Lebanon; \\ fn14@aub.edu.lb \\ 5 Family Health Promotion Centre, Sharjah 27272, UAE; Hessa.ALGhazal@scf.shj.ae \\ * Correspondence: paul.mcjarrow@fonterra.com; Tel.: +64-6-3504649 \\ + Both authors contributed equally to this manuscript.
}

Received: 1 August 2019; Accepted: 18 September 2019; Published: 8 October 2019

\begin{abstract}
Human milk oligosaccharides (HMOs), phospholipids (PLs), and gangliosides (GAs) are components of human breast milk that play important roles in the development of the rapidly growing infant. The differences in these components in human milk from the United Arab Emirates (UAE) were studied in a cross-sectional trial. High-performance liquid chromatography-mass spectrometry was used to determine HMO, PL, and GA concentrations in transitional (5-15 days) and mature (at 6 months post-partum) breast milk of mothers of the United Arab Emirates (UAE). The results showed that the average HMO (12 species), PL (7 species), and GA ( 2 species) concentrations quantified in the UAE mothers' transitional milk samples were (in mg/L) $8204 \pm 2389,269 \pm 89$, and $21.18 \pm 11.46$, respectively, while in mature milk, the respective concentrations were (in $\mathrm{mg} / \mathrm{L}$ ) $3905 \pm 1466,220 \pm 85$, and $20.18 \pm 9.75$. The individual HMO concentrations measured in this study were all significantly higher in transitional milk than in mature milk, except for 3 fucosyllactose, which was higher in mature milk. In this study, secretor and non-secretor phenotype mothers showed no significant difference in the total HMO concentration. For the PL and GA components, changes in the individual PL and GA species distribution was observed between transitional milk and mature milk. However, the changes were within the ranges found in human milk from other regions.
\end{abstract}

Keywords: human milk; human milk oligosaccharides; phospholipids; sphingomyelin; gangliosides; LC-MS 


\section{Introduction}

Human milk (HM) is the complete food source for infants, providing all the nutrients required for growth in the early stages of life. There has been long interest in the composition of human milk and its changes with lactation and differences between mothers and between populations in different geographical locations or with different diets. Changes in the macronutrient composition of HM with respect to fat, protein, and lactose in different population cohorts have been investigated for many years [1].

As a group, human milk oligosaccharides (HMOs) are a major component of HM, forming the third most dominant component (12-18.6 g/L) after lactose (55-70 g/L) and fat 20-60 g/L) [2,3], and on average having a higher concentration than protein. However, whether they are a macronutrient in sensu stricto is open to interpretation [4]. Phospholipids (PLs) and gangliosides (GAs), which are constituents of the milkfat globule membrane (MFGM) that surrounds the lipid droplet, are minor components. Increasing evidence indicates that HMOs, PLs, and GAs play critical roles in the development of the growing infants and have been of increasing interest in recent years as infant formula manufacturers look to humanise their formulations.

HMOs are shown to play significant biological roles as prebiotics, antimicrobials, and immune modulators [5-16] for the growing infant. To date, there are over 200 oligosaccharides [17] reported in HM. One impact on the HMO profile from an individual mother is the absence (non-secretor) or presence (secretor) of a fully functional $\alpha$ - $(1,2)$-fucosyltransferase 2 , which is coded by the FUT2 gene; milk produced by non-secretor mothers contains low concentrations of $2^{\prime}$-fucosyllactose (2'FL) as well as lacto-N-fucopentaose I (LNFP I) [5,18].

In addition to their essential roles in cell membrane structural integrity, PLs play critical roles in lung and brain development in the growing infant [19-23]. The PLs in HM are mainly found in the tri-layer of the MFGM and consist of sphingomyelins (SMs) and the glycerophospholipids phosphatidyl choline (PC) and its lyso species (L-PC), phosphatidyl ethanolamine (PE) and its lyso species (L-PE), phosphatidyl inositol (PI), and phosphatidyl serine (PS).

GAs are also important in neurological development, memory formation, and synaptic signal transduction, and are implicated in regulating the immune system and supporting gut maturation in the new born [24-26].

There are recent studies that report the changes in HMOs [27-30], PLs [31-33], and GAs [32-35] across lactation for various population cohorts; however, to our knowledge, there is no specific study reported for the UAE or other Middle Eastern populations. In this study, the HMO, PL, and GA concentrations in transitional (5-15 days) and mature milk (at 6 months post-partum) were measured in a cross section of UAE mothers' breast milk samples, collected from a wider mother-infant study cohort (MISC) [36]. The information obtained from this study allows comparison with other similar studies on HMO, PL, and GA levels in HM from other population cohorts to better address the hypothesis that geography and ethnicity impact the levels of these HM bioactives [28].

\section{Materials and Methods}

\subsection{Study Setting and Population}

A randomly selected subsample of breast milk samples (transitional milk period, days 5 to 15 post-partum, $n=41$, and mature milk at 6 months post-partum, $n=40$ ) were made from a large cohort collected as part of the MISC in the UAE to comprehensively investigate maternal and infant factors in relation to child health outcomes, as well as early-life determinants of non-communicable diseases, through integration of sociodemographic, dietary, lifestyle, anthropometric, and biological and cognitive data [36]. 
Arab participants were recruited from antenatal clinics in three main public governmental hospitals, and seven primary health care clinics and mother and child centres in the Emirates of Sharjah, Dubai, and Ajman. The inclusion criteria were pregnant women who were Emirati or Arab expatriate; aged 19-40 years; singleton pregnancy; within the third trimester of pregnancy (27-42 weeks of gestation); free of chronic diseases (including diabetes, hypertension, kidney disease, cancer, and others), autoimmune disorders, infections with the human immunodeficiency virus, or hepatitis in preconception; receiving antenatal care in any of the above-mentioned clinics; and expected to give birth in a participating public hospital and remaining in the UAE during the timeline of the study. The exclusion criteria were as follows: multiple pregnancy, high risk pregnancy or pre-eclampsia, and history of chronic diseases [36].

The study was approved by the Research and Ethics Committee, University of Sharjah (REC/14/01/1505) and by Al Qassimi Clinical Research Centre Ethical Research Committee (REC Reference Number: 215 12015-03), by the Ministry of Health Ethical Research Committee (R02), and by Dubai Health Authority (DSREC-0/2016).

\subsection{Phospholipid, Ganglioside, and Oligosaccharide Analysis}

Extraction of HM samples and analysis using HPLC-MS was as described previously for PLs [31] and GAs [34]. Briefly, $0.25 \mathrm{~mL}$ of HM samples was extracted using the modified Svennerholm and Fredman [37] method described by Fong et al. [38]. The non-polar (lower) phase was diluted to $5 \mathrm{~mL}$ with choroform/methanol (1:2) and an aliquot was used for quantification of PC, PS, PI, PE, SM, L-PC, and L-PE. Separation and quantification were as described previously [38] with individual PL species separated using an ACQUITY UPLC system (Waters, Milford, MA, USA) equipped with an APS-2 Hypersil column $(150 \mathrm{~mm} \times 2.1 \mathrm{~mm}, 3 \mathrm{Um}$, Thermo Electron Corporation, Waltham, MA, USA). The eluate from the HPLC was directed into a TSQ Quantum mass spectrometry (Thermo Electron Corporation, Waltham, MA, USA) with individual PL species detected either by precursor ion or neutral loss experiments [38]. The polar (upper) phase from the extraction was diluted to $10 \mathrm{~mL}$ with methanol/water (1:1), and then GA classes (disialoganglioisde 3 (GD3) and monosialoganglioside 3 (GM3)) were separated on an Agilent 1100 series HPLC system (Santa Clara, CA, USA) equipped with an APS-2 Hypersil column $(150 \mathrm{~mm} \times 2.1 \mathrm{~mm}, 3 \mathrm{~mm})$, interfaced to a SCIEX 6500 QTrap mass spectrometer (AB SCIEX, Framingham, MA, USA) and quantified as described by Ma et al. [26] using multiple reaction monitoring in negative mode.

HMOs (3'-sialyllactose (3'SL), 6'-sialyllactose (6'SL), 6'-sialyllactosamine (6'SLN), disialyllactose (DSL), 3'-sialyl-3-fucosyllactose (3'S3FL), LS-tetrasaccharide a/b (LSTa/b), LS-tetrasaccharide (LSTc), lacto-N-neotetraose (LNnT), lacto-N-tetraose (LNT), Lacto-N-fucopentaose (LNFP total against LNFP I as standard), 2'-fucosyllactose (2'FL), and 3-fucosyllactose (3FL)); were analysed for, and in all cases, the sialic acid is $\mathrm{N}$-acetyl neuraminic acid. HMOs were separated using a Luna hydrophilic interaction liquid chromatography column $(150 \mathrm{~mm} \times 2.1 \mathrm{~mm}, 3 \mathrm{um}$, Phenomenex, Torrence, CA, USA) on an Agilent 1100 series HPLC [30]. The HPLC system was coupled to a SCIEX 6500 QTrap mass spectrometer, operated in negative ion mode, and HMOs were quantified as described [30] using 3'-sialyllactosamine as an internal standard.

\subsection{Statistical Analysis}

Statistical analysis was conducted using one-way analysis of variance (ANOVA), where difference among the means is significant when $p<0.05$ (MiniTab Release 17.2.1 2016, MiniTab Inc., State College, PA, USA). 


\section{Results}

\section{1. $H M O$}

Seven acidic (3'SL, 6'SL, 6'SLN, 3'S3FL, DSL, LSTa/b, and LSTc) and five neutral (LNnT, LNT, LNFP (total), 2'FL, and 3FL) oligosaccharides were measured.

The average HMO concentration in transitional milk $(8204 \pm 2389 \mathrm{mg} / \mathrm{L}$; Table 1) was significantly higher than that measured in mature milk $(3905 \pm 1466 \mathrm{mg} / \mathrm{L}$; Table 1$)$. This trend was also reflected at the individual HMO level (Table 1). When secretor and non-secretor milk samples were considered separately (based on a non-secretor milk having a 2'FL concentration $<50 \mathrm{mg} / \mathrm{L}$ ), the total HMO concentrations for both groups were not significantly different for either transitional or mature milk (Table 1).

The proportion of the acidic HMOs in transitional milk (18\%) was higher than that measured in mature milk (7\%); concomitantly, the neutral HMOs in transitional milk were $82 \%$ of total HMOs measured, compared with $93 \%$ in mature milk. When considered separately, secretors and non-secretors were not significantly different in this aspect. The HMO species for which there was a significant difference in concentration between secretor and non-secretor milk samples were 2'FL, 3FL, and 3'S3FL (Table 1). The secretor milk samples were higher in 2'FL and lower in 3FL and 3'S3FL compared with non-secretor milk samples.

\subsection{Phospholipids}

The average total PL concentration $( \pm \mathrm{SD})$ measured in the transitional milk $(269.0 \pm 89.2 \mathrm{mg} / \mathrm{L})$ was significantly $(p<0.05)$ higher than that measured for mature milk $(219.6 \pm 85.0 \mathrm{mg} / \mathrm{L}$, Table 2$)$. The concentration of PE, SM, and L-PE did not change significantly $(p>0.05)$ between transitional and mature milk, but PI, PC, PS, and L-PC decreased significantly in concentration in mature milk (Table 2).

The relative distribution of the five different PL classes (PI, PC, PE, PS, and SM) and L-PC and L-PE is presented in Table 2. Because of the changes in individual PL species concentration, significant changes in the relative distribution of PL classes were observed, with PE increasing from $25 \%$ in transitional milk to $36 \%$ in mature milk (6 months post-partum), while PC and PS decreased from $25 \%$ to $14 \%$ and $11 \%$ to $7 \%$, respectively. SM remained the dominant PL class during both lactation milk time points, and only increased slightly (Table 1). Little change in the PI distribution was observed over the two-time points, decreasing from $4 \%$ to $3 \%$.

\subsection{Gangliosides}

The average total GA (TGA) concentration measured in the UAE mothers' transitional milk $(21.2 \pm 11.46 \mathrm{mg} / \mathrm{L})$ and mature milk $(20.2 \pm 9.8 \mathrm{mg} / \mathrm{L})$ was not significantly different $(p>0.05)$ across the two-time points. However, the relative distribution of ganglioside classes, GD3 and GM3, changed across the two-time points from $56 \%$ and $44 \%$, respectively, for transition milk, to $9 \%$ and 91\% respectively, for mature milk (Table 2), with both GM3 and GD3 showing significant changes in concentration. 
Table 1. Human milk oligosaccharide (HMO) concentration in transitional and mature human milk from United Arab Emirates (UAE) mothers. 3'SL, $3^{\prime}$-sialyllactose; 6'SL, 6'-sialyllactose; 6'SLN, 6'-sialyllactosamine; DSL, disialyllactose; 3'S3FL, 3'-sialyl-3-fucosyllactose; LSTa/b, LS-tetrasaccharide a/b; LSTc, LS-tetrasaccharide; LNnT, lacto-N-neotetraose; LNT, lacto-N-tetraose LNFP, lacto-N-fucopentaose I; 2'FL, 2'-fucosyllactose; 3FL, 3-fucosyllactose.

\begin{tabular}{|c|c|c|c|c|c|c|c|c|c|c|c|c|c|}
\hline Sample & $3^{\prime} \mathrm{SL}$ & $6^{\prime} \mathrm{SL}$ & $6^{\prime}$ SLN & DSL & 3'S3FL & $\mathrm{LSTa} / \mathrm{b}$ & LSTc & $2^{\prime} \mathrm{FL}$ & $3 F$ & LNnT & LNT & LNFP & Total HMO \\
\hline $\begin{array}{l}\text { Transitional } \\
\text { (all) }(n=41)\end{array}$ & $226 \pm 107^{a}$ & $621 \pm 212^{a}$ & $15 \pm 15^{\mathrm{a}}$ & $2.2 \pm 2.3^{\mathrm{a}}$ & $19 \pm 21^{\mathrm{a}}$ & $104 \pm 46^{\mathrm{a}}$ & $488 \pm 224^{a}$ & $2021 \pm 1776^{a}$ & $581 \pm 868^{a}$ & $765 \pm 350^{\mathrm{a}}$ & $1429 \pm 693^{a}$ & $1932 \pm 762^{\mathrm{a}}$ & $8204 \pm 2388^{a}$ \\
\hline Non-secretor & $256 \pm 144$ & $562 \pm 232$ & $20 \pm 23$ & $1.8 \pm 1.9$ & $48 \pm 49$ & $124 \pm 52$ & $456 \pm 243$ & $4.3 \pm 8.6$ & $1599 \pm 119$ & $990 \pm 524$ & $1917 \pm 973$ & $1490 \pm 528$ & $7466 \pm 1812$ \\
\hline Secretor & $216 \pm 91$ & $643 \pm 204$ & $13 \pm 11$ & $2.4 \pm 2.4$ & $8.1 \pm 7.0$ & $98 \pm 42$ & $500 \pm 220$ & $2761 \pm 1497^{\#}$ & $208 \pm 112^{\#}$ & $682 \pm 220$ & $1250 \pm 460$ & $2094 \pm 777^{\#}$ & $8475 \pm 2541$ \\
\hline $\begin{array}{c}\text { Mature (all) } \\
(n=40)\end{array}$ & $134 \pm 69^{b}$ & $91 \pm 108^{b}$ & $5 \pm 1^{b}$ & $0.2 \pm 0.4^{b}$ & $10 \pm 14$ & $31 \pm 25^{b}$ & $11 \pm 0$ & $997 \pm 003$ & $1194 \pm 106^{b}$ & $250 \pm 188^{b}$ & $504 \pm 337^{b}$ & $650 \pm 416^{\mathrm{b}}$ & $3876 \pm 1403^{b}$ \\
\hline Non-secretor & $181 \pm 98$ & $81 \pm 52$ & $4.9 \pm 2.2$ & $0.1 \pm 0.2$ & $25 \pm 20$ & $28 \pm 18$ & $6.7 \pm 5.3$ & $4.0 \pm 2.8$ & $2526 \pm 113$ & $187 \pm 113$ & $420 \pm 276$ & $548 \pm 300$ & $4009 \pm 1104$ \\
\hline Secretor & $116 \pm 44$ & $95 \pm 124$ & $4.4 \pm 0.6$ & $0.3 \pm 0.5$ & $4.6 \pm 2.4^{\text {\# }}$ & $32 \pm 28$ & $13 \pm 8^{\#}$ & $1374 \pm 746^{\#}$ & $688 \pm 398^{\#}$ & $273 \pm 207$ & $536 \pm 357$ & $689 \pm 451$ & $3826 \pm 1515$ \\
\hline
\end{tabular}

Values (in $\mathrm{mg} / \mathrm{L}$ ) are means \pm standard deviation. Different symbol pairings signify statistically significant values $(p<0.05)$; when comparing transitional and mature milk individual HMO and total, differences in groups are represented by $a, b . \#$ is used if the difference between secretor/non-secretor groups is significant.

Table 2. Phospholipid (PL) and ganglioside (GA) concentrations in transitional and mature breast milk. SM, sphingomyelins; PC, phosphatidyl choline (PC); L-PC, PC lyso species; PE, phosphatidyl ethanolamine; L-PE, PE lyso species; PI, phosphatidyl inositol; PS, phosphatidyl serine; GD3, disialoganglioisde 3; GM3, monosialoganglioside 3.

\begin{tabular}{|c|c|c|c|c|c|c|c|c|c|c|c|}
\hline \multirow{2}{*}{ Time Point } & \multicolumn{8}{|c|}{ Phospholipids } & \multicolumn{3}{|c|}{ Gangliosides } \\
\hline & PI & PE & PC & SM & PS & L-PE & L-PC & Total PL & GM3 & GD3 & Total GA \\
\hline $\begin{array}{c}\text { Transitional } \\
\quad(n=41)\end{array}$ & $\begin{array}{c}11.2 \pm 5.5^{\mathrm{a}} \\
(4 \%)\end{array}$ & $\begin{array}{c}66.3 \pm 27.16 \\
\text { a }(25 \%)\end{array}$ & $\begin{array}{c}66.4 \pm 32.87 \\
\text { a }(25 \%)\end{array}$ & $\begin{array}{c}91.2 \pm 26.38 \\
\text { a }(34 \%)\end{array}$ & $\begin{array}{c}28.5 \pm 13.29 \\
\text { a }(7 \%)\end{array}$ & $\begin{array}{c}3.7 \pm 2.37^{\mathrm{a}} \\
(1.4 \%)\end{array}$ & $\begin{array}{c}1.7 \pm 0.98^{\mathrm{a}} \\
(0.6 \%)\end{array}$ & $269.0 \pm 89.2^{a}$ & $\begin{array}{c}9.47 \pm 8.37 \\
\text { a }(45 \%)\end{array}$ & $\begin{array}{c}11.71 \pm 9.46 \\
\text { a }(55 \%)\end{array}$ & $21.18 \pm 11.46^{\mathrm{a}}$ \\
\hline $\begin{array}{l}\text { Mature } \\
(n=40)\end{array}$ & $\begin{array}{c}6.5 \pm 3.61^{b} \\
(3 \%)\end{array}$ & $\begin{array}{c}80.0 \pm 35.35 \\
\text { a }(36 \%)\end{array}$ & $\begin{array}{c}30.2 \pm 22.07 \\
\mathrm{~b}(14 \%)\end{array}$ & $\begin{array}{c}82.9 \pm 29.21 \\
\text { a }(38 \%)\end{array}$ & $\begin{array}{c}16.1 \pm 6.99 \\
\text { b }(7 \%)\end{array}$ & $\begin{array}{c}3.1 \pm 1.99^{\mathrm{a}} \\
(1.4 \%)\end{array}$ & $\begin{array}{c}0.9 \pm 0.63^{b} \\
(0.4 \%)\end{array}$ & $219.6 \pm 85.0^{b}$ & $\begin{array}{c}18.62 \pm 9.69 \\
\mathrm{~b}(92 \%)\end{array}$ & $\begin{array}{c}1.57 \pm 2.24 \\
\mathrm{~b}(8 \%)\end{array}$ & $20.18 \pm 9.75^{a}$ \\
\hline
\end{tabular}

Values (in $\mathrm{mg} / \mathrm{L}$ ) are means \pm standard deviation; the relative distribution (\%) of the individual phospholipid classes and ganglioside classes are in parenthesis. In a column, values with the same superscript indicate no significant difference $(p>0.05)$ between the transitional and mature milk samples; when comparing transitional and mature milk individual phospholipids and gangliosides and total, differences in concentration are represented by ${ }^{\mathrm{a}, \mathrm{b}}$. \# is used for when the differences in the relative percentages of the individual phospholipids and gangliosides is significant between the transitional and mature milk. 


\section{Discussion}

HM is considered the "gold standard" for an infant's nutrition, to which infant formula manufacturers strive to emulate in both nutrient composition and performance. HM composition varies considerably between individual mothers and over lactation, and so could be considered to be personalised to each infant that is breastfed. Various factors such as diet, geography, ethnicity, milk collection time, and genetics have been implicated to have a significant influence on the HMO, PL, and GA composition in HM, but most of the data obtained to date indicate that the stage of lactation is perhaps the primary factor that has the greatest influence on HM composition [27-29,39]. There are several recent studies reporting the composition of $\mathrm{HM}$, trying to gain a better understanding of the changes in the HMOs and complex lipids (PLs and GAs) through lactation of different geographical population cohorts $[28,31,32,34,35,39,40]$. However, this is the first study that looks at the transitional and mature milk from UAE mothers, helping to address geographical variation in HMOs, PLs, and GAs.

\subsection{Human Milk Oligosaccharides}

The UAE mothers' transitional breast milk samples had significantly higher average total HMO concentrations $(8204 \pm 2389 \mathrm{mg} / \mathrm{L})$ compared with the mature milk samples $(3876 \pm 1403 \mathrm{mg} / \mathrm{L})$. The largest decrease in the HMOs over these two lactation timepoints was observed with the acidic oligosaccharide, LSTc, which decreased by $98 \%$ from $488 \pm 224 \mathrm{mg} / \mathrm{mL}$ in transitional milk to $11 \mathrm{mg} / \mathrm{L}$ in the six months post-partum mature milk (Table 1). The only HMO to increase across this period was 3FL (Table 1). This trend is in line with lactational trend data reported in the literature $[27,29,30]$ (Figure 1). While only five neutral oligosaccharides (2'FL, 3FL, LNT, LNnT, and total LNFP) were measured in this study, they made up a significant proportion $(82 \%$ and $93 \%$ for transitional and mature milk, respectively) of the total HMOs measured in this study, with the acidic HMOs making up $18 \%$ and $7 \%$ for transitional and mature milk, respectively. This finding is consistent with those reported by Ma et al. [30] for their Malaysian and Chinese cohort of $89 \%-91 \%$ and $8.5 \%-11 \%$ of neutral and acidic HMOs, respectively, and other similar studies [27-29], despite differences in the range of HMOs and respective concentrations being different.

The individual HMO levels measured in this study for the UAE breast milk samples were also in a range similar to that reported by Ma et al. [30] for Chinese and Malaysian mothers (Table 3 and Figure 1); and Larsson et al. [41], Coppa et al. [42], Bao et al. [43], and Austin et al. [29] for the common HMOs measured for the corresponding time points, except for 3'SL, LNT, and LNnT where Austin et al. [29] reported lower HMO lactational results (Table 3 and Figure 1).

HMOs have been implicated not just to provide anti-infective protection for the infant, but also as being involved as immune modulators, and may play a key role in gut maturation of the rapidly growing infant. Higher $\mathrm{HMO}$ concentrations in colostrum and transitional milk may be the consequence of increased protection required for the vulnerable infant during the early few days of life. The changes in HMO levels over the course of lactation $[29,30]$ may reflect changes in the development stages of the growing infant, and a requirement for specific compositions of these HMOs.

On the basis of the $2^{\prime} \mathrm{FL}$ concentrations, $26 \%$ of the UAE mothers in this cohort expressed a non-secretor phenotype, having a $2^{\prime} \mathrm{FL}$ concentration $<50 \mathrm{mg} / \mathrm{L}$ in their breast milk samples $[29,44]$. $2^{\prime} \mathrm{FL}$ (and LNFP I) are products of $\alpha$-(1,2)-fucosyltransferase 2 , which is coded by the FUT2 gene that is supposedly non-functional in non-secretor mothers. However, in the study of Austin et al. [20], 2'FL was found to be not completely absent in the non-secretor mothers, as was the case in this study. The secretor/non-secretor frequency is known to vary with geography and racial difference, with $22.5 \%$ non-secretor phenotype reported for the Han Chinese population, Eastern China region [29]; $37 \%$ reported for the Chinese cohort (Guangzhou); and 17\% reported for Malay mothers [30]. The typical frequency of non-secretor phenotype reported by Azad et al. [39] was 28\% for Caucasian mothers, while Asian mothers had higher non-secretor frequency at $40 \%$; however, the Asian mothers' sub-ethnic groups were not defined. There is no current information as to the non-secretor frequency for the UAE population. Azad et al. [30] also reported that the non-secretor group had significantly less HMOs 
than the secretor group. For the HMOs measured in this study, however, there was no significant difference $(p>0.05)$ in the average total HMOs between secretor and non-secretor mothers for either their transitional milk ( $8292 \pm 2516 \mathrm{mg} / \mathrm{L}$ versus $6994 \pm 1905 \mathrm{mg} / \mathrm{L}$, respectively) or their mature milk $(4289 \pm 1791 \mathrm{mg} / \mathrm{L}$ versus $4317 \pm 1857 \mathrm{mg} / \mathrm{L}$, respectively) (Table 1).

Period of lactation (months)
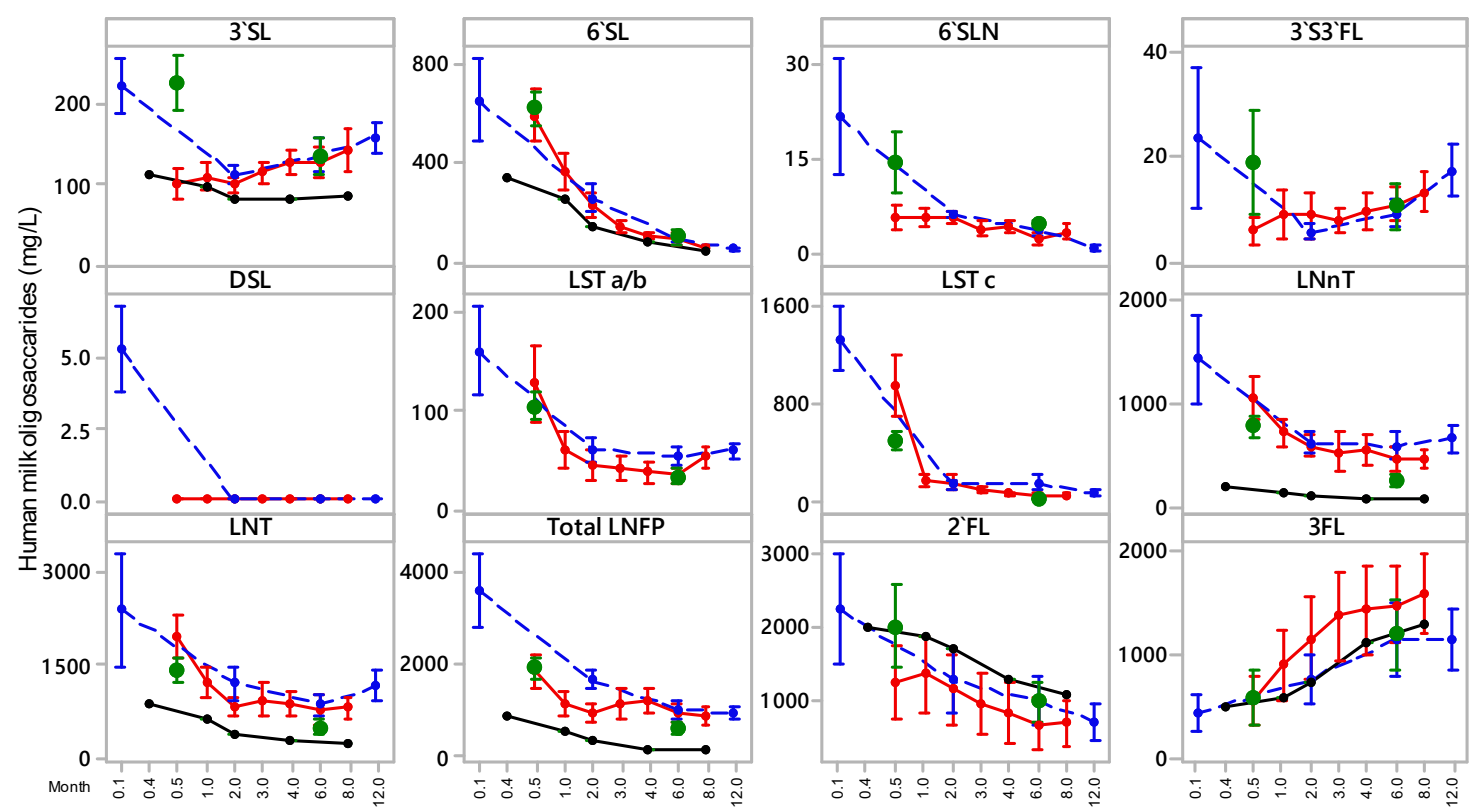

Figure 1. Human milk oligosaccharide (HMO) concentrations in the United Arab Emirates (UAE) mothers' milk (๑) across the transitional milk and mature milk periods, plotted against the lactational trend reported by Ma et al. [30] for a Chinese cohort (๑) and Malaysian cohort (๑), and by Austin et al. [29] for a Chinese cohort (•). 3'SL, 3'-sialyllactose; 6'SL, 6'-sialyllactose; 6'SLN, 6'-sialyllactosamine; DSL, disialyllactose; 3'S3FL, 3'-sialyl-3-fucosyllactose; LSTa/b, LS-tetrasaccharide a/b; LSTc, LStetrasaccharide; LNnT, lacto-N-neotetraose; LNT, lacto-N-tetraose LNFP, lacto-N-fucopentaose I; 2'FL, 2'-fucosyllactose; 3FL, 3-fucosyllactose.

One important consideration in assessing crude population figures for HMO species is the impact that the percentage of non-secretors in each study population has on the average or mean 2'FL and 3FL concentrations that would be reported for the full cohort; the higher the percentage of non-secretors in a population, the lower the average $2^{\prime} \mathrm{FL}$ and higher the average 3FL concentrations for the cohort as a whole. Furthermore, it is not only the crude 2'FL and 3FL figures that are impacted, but also the figures for other oligosaccharides such as LNFP I and 3'S3FL. For example, in this study, the mature milk results for the full cohort showed that 2'FL and 3FL concentrations are relatively similar, which was also shown by Ma et al. [30] and Austin et al. [29], but if the non-secretor percentage was lower, then 3FL would be lower than 2'FL at later points in lactation, as evidenced in the limited data of Larsson et al. [41], which is the analysis of secretors alone, and the results of this study. Figure 1 also emphasises the impact of lactation on interpreting which oligosaccharides are in highest concentration, because, at six months in all four cohorts (two Chinese, one Malaysian, and one UAE), the concentrations of 3FL and $2^{\prime} \mathrm{FL}$ are very similar. 
Table 3. Human milk oligosaccharide mean concentrations reported in the literature for both transitional and mature milk about six months post partum (mg/L, except for Austin et al. [20], which is $\mathrm{mg} / \mathrm{kg}$ ).

\begin{tabular}{|c|c|c|c|c|c|c|c|c|c|c|c|c|c|c|}
\hline Reference & Milk (Post Partum) & $\mathbf{n}$ & $3^{\prime} \mathrm{SL}$ & $6^{\prime} \mathrm{SL}$ & $6^{\prime}$ SLN & DSL & 3'S3FL & LSTa/b & LSTc & $2^{\prime} \mathrm{FL}$ & $3 F L$ & LNnT & LNT & Total LNFP \\
\hline Larsson et al. [41] ${ }^{\mathrm{a}, \mathrm{b}}$ Denmark & Mature (5 month) & 15 & 492 & 156 & & & & 149 & 33 & 2989 & 229 & 578 & 703 & 2692 \\
\hline Coppa et al. [42] Italy & Transition (4 days) & 18 & & & & & & & & 3930 & 340 & 2040 & 840 & 1650 \\
\hline Bao et al. [43] USA & Transition (9-21 days) & & 76 & 396 & & & & $74^{\mathrm{c}}$ & 148 & & & & & \\
\hline \multirow{2}{*}{ Austin et al. [20] (Table 4) China } & Transition (5-11 days) & 90 & 110 & 340 & & & & & & 2600 & 510 & 180 & 880 & 1157 \\
\hline & Mature ( $4-8$ months) & 90 & 83 & 45 & & & & & & 1300 & 1300 & 59 & 250 & 199 \\
\hline \multirow{2}{*}{ Ma et al. [21] China } & Transition (14 days) & 20 & 100 & 593 & 6 & 3 & 6 & 127 & 941 & 1281 & 543 & 1033 & 1979 & 1870 \\
\hline & Mature (6 months) & 20 & 127 & 83 & 2 & 0 & 11 & 33 & 47 & 704 & 1476 & 446 & 785 & 945 \\
\hline Ma et al. [21] Malaysia & Mature (6 months) & 21 & 135 & 84 & 4 & 0 & 9 & 84 & 145 & 1003 & 1146 & 571 & 867 & 1036 \\
\hline This study UAE & Transition (6-14 days) & 41 & 226 & 621 & 15 & 2 & 19 & 104 & 488 & 2021 & 581 & 765 & 1429 & 1932 \\
\hline This study UAE & Mature (6 months) & 40 & 134 & 91 & 5 & 0 & 10 & 31 & 11 & 997 & 1194 & 250 & 504 & 650 \\
\hline
\end{tabular}

a secretors only. ${ }^{\mathrm{b}}$ calculated from $\mathrm{nmol} / \mathrm{mL}$ data. ${ }^{\mathrm{c}} \mathrm{LSTb}$ alone. 


\subsection{Phospholipids}

The average total PL concentrations observed with HM samples of UAE mothers were within the typical ranges reported for human breast milk for other geographical population cohorts (Table 4). In this study, the UAE transitional milk had an average total PL concentration that was significantly higher $(p<0.05)$ than that measured for the six-month mature milk. While this trend is consistent with the majority of the published data $[31,33,45-48]$, the trend reported from some studies showed the total PL concentration in colostrum and transitional milk was either much lower than [49-51] or the same as [52] that in mature milk (Table 4).

At the individual PL class level, changes in the relative distribution of the individual PL classes were observed over the transitional milk and mature milk periods (Figure 1). There was a significant increase in the relative amount of PE from $25 \%$ in transitional milk to $36 \%$ in the UAE mature milk samples, while PC and PS both decreased, the former from $25 \%$ to $14 \%$ and the latter from $11 \%$ to $7 \%$. SM increased only slightly, while PI decreased slightly. Similarly, changes in the relative distribution between transition milk and mature milk was observed for a Malaysian HM cohort [31] (Figure 2). In contrast, however, the PL distribution was relatively constant for Spanish [34] and Chinese [24] breast milk cohorts (Figure 2).

Table 4. Human milk phospholipid concentration reported in the literature for both transitional and mature milk (modified from Ma et al. [31]) ${ }^{\mathrm{a}}$.

\begin{tabular}{|c|c|c|c|}
\hline \multicolumn{2}{|c|}{ Total PL Ranges (mg/L) } & \multirow{2}{*}{ Country } & \multirow{2}{*}{ Reference } \\
\hline Transitional Milk & Mature Milk & & \\
\hline $390 \pm 50-440 \pm 73(8-15,20)$ & $370 \pm 106-405 \pm 80(22-36,40)$ & Germany & Harzer et al. [52] \\
\hline $310 \pm 30(11,5)$ & $270 \pm 30(23,5$ pooled $)$ & USA & Bitman et al. [47] \\
\hline $158(11,17)$ & $114(23,19)$ & Spain & Sala-Vila et al. [48] \\
\hline $148(7,6)$ & $133-227(20-84,6)$ & USA & Bitman et al. [49] \\
\hline $973(14,10)$ & $1023-1298(42-112,10)$ & USA & Clark et al. [50] \\
\hline $185(6-15,45)$ & $182(>16,45)$ & Denmark & Zou et al. [51] \\
\hline $550 \pm 260(6-10,7)$ & $450 \pm 260(30,16)$ & France & Gracia et al. [45] \\
\hline & $230 \pm 49-242 \pm 82(30-120,50)$ & Singapore & Thakkar et al. [32] \\
\hline $437 \pm 23-535 \pm 26(6-15,44)$ & $260 \pm 3-422 \pm 13(16-360,44)$ & Spain & Claumarchirant et al. [46] \\
\hline $266 \pm 57(6-14,12)$ & $170 \pm 80-219 \pm 92(60-365,132)$ & Malaysia & Ma et al. [31] \\
\hline $285 \pm 144(6-15,81)$ & $242 \pm 114(16-240,345)$ & China & Guiffrida et al. [33] \\
\hline $269 \pm 89(6-14,41)$ & $220 \pm 85(180,40)$ & UAE & This study \\
\hline
\end{tabular}

${ }^{a}$ Lactational period, in days, and number of samples are given in parentheses. Data from Sala-Vila et al. [48] recalculated from total phospholipid data provided using average molecular masses of 758.4, 864.4, 787.1, 737.6, and 754.4 for PC, PI, PS, PE, and SM, respectively; data from Bitman et al. [49] recalculated from graph using termed mothers only.

However, across the mature milk period, three recent studies [31,32,46] and two earlier studies [49,52] showed that the individual PL class distribution remained relatively constant through the mature milk period, despite changes in their absolute concentrations.

Variation in absolute PL concentrations may be attributable to a variety of factors, such as time of sampling protocols (full breast expression, time of sampling, and breast variation [53]), diet, geographic, and even metabolic stage and gestational age at birth, in addition to different analytical methods used [54-56]. However, the fact that the relative distribution of the individual PL class remains constant through the mature milk period indicates that some metabolic controls are maintained over the biosynthesis of these PL classes, perhaps to maintain the integrity of the MFGM structure.

Changes in the individual PL distribution observed between early milk and mature milk may be the consequence of the changing structure. It is reported that colostrum and transitional milk has much larger fat droplet size than that of mature milk [57]. In fact, Cohen et al. [58] reported the phospholipid composition of the mammary epithelial cell regulated the lipid droplet size, rather than the cellular triglyceride content; this phospholipid composition is critical in maintaining membrane structure integrity as the lipid droplet size changes. 


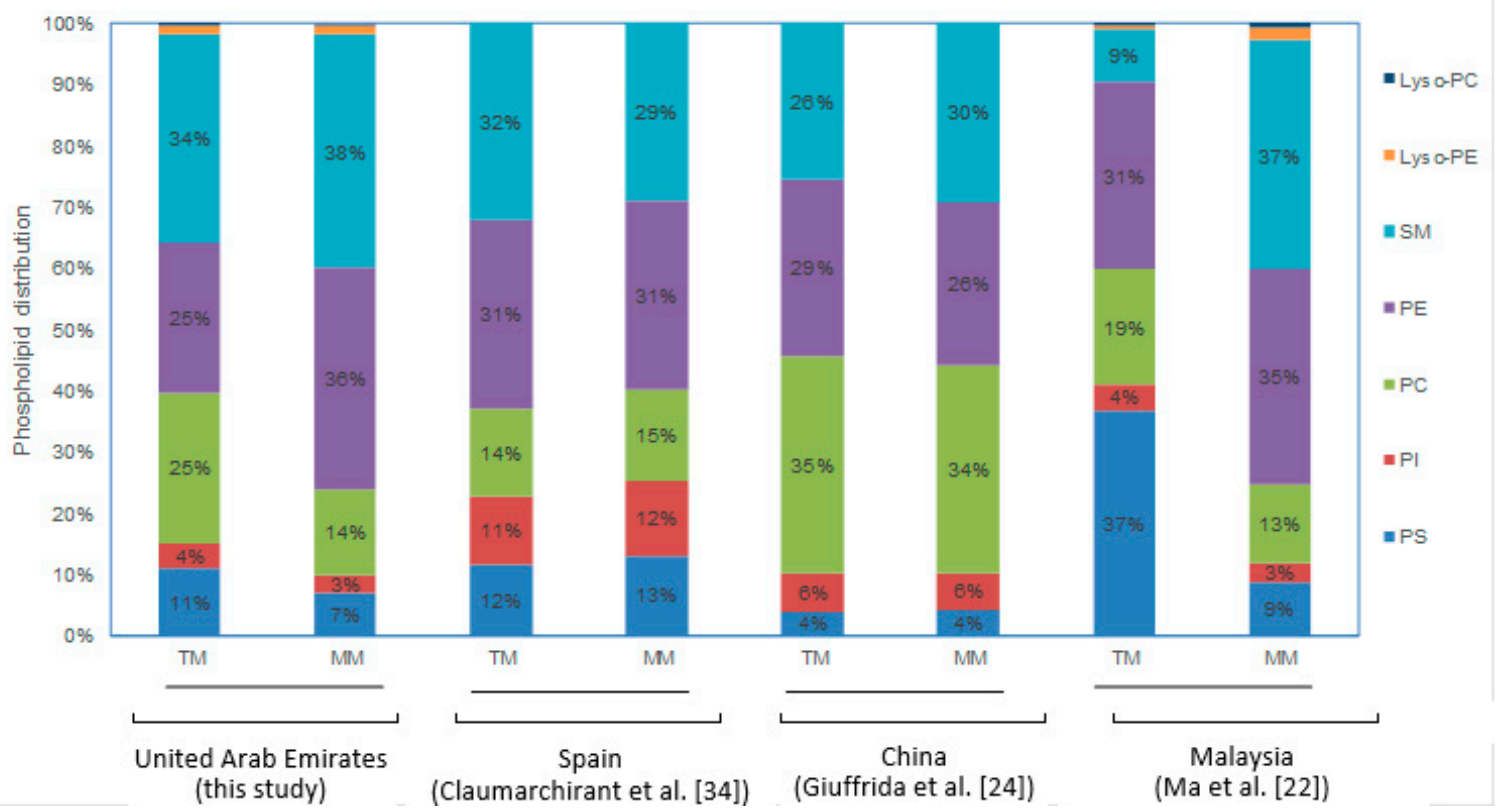

Figure 2. Distribution of phospholipid classes in transitional milk (TM) and mature milk (MM; six months post-partum) in UAE mothers' milk, and from other geographic cohorts. SM, sphingomyelins; PC, phosphatidyl choline (PC); L-PC, PC lyso species; PE, phosphatidyl ethanolamine; L-PE, PE lyso species; PI, phosphatidyl inositol; PS, phosphatidyl serine.

\subsection{Gangliosides}

In HM, GAs are present predominantly as the GM3 and GD3 classes (which have the same polar head group, but different sphingosine and fatty acid). Typically, GD3 is present at relatively high concentrations in colostrum and transitional HM, making up approximately $30 \%-80 \%$ of the TGAs, but decreasing to $8 \%-25 \%$ by four to six months post-partum. Conversely, the relative proportion of GM3 is higher in mature milk [33,35,59-61].

However, there is no clear consistent lactational trend observed for TGA concentration. While a few studies show colostrum and transitional milk to contain the highest TGA concentration [34,59], other studies show the opposite $[60,62]$. Similarly, the TGA lactation trend over the mature milk period is also not clear. While the studies of Thakkar et al. [32] and Ma et al. [34] showed a gradual increase in the TGA level over the mature milk period (of four months and eight months duration, respectively), from the data published for the Malaysian cohort [34], this gradual increase did not appear to be sustained: the average TGA levels dropped from $\sim 25.3 \pm 15.7 \mathrm{mg} / \mathrm{L}$ at 6 months to $16.6 \pm 8.5 \mathrm{mg} / \mathrm{L}$ at around 12 months post-partum.

In this study, there was no significant difference between the average TGA results measured between the transitional milk $(21.18 \pm 11.46)$ and the mature milk period $(20.18 \pm 9.75)$, with GD3 making up $55 \%$ of the TGAs in transition milk, decreasing to $8 \%$ at six months post-partum. The change in the GA class distribution is consistent across other published cohort studies [34,35] (Table 5), suggesting that the biosynthesis of GAs is under metabolic control, and different classes may be required for different stages of the development and growth for the breast fed infant. Interestingly, Thakkar et al. [32] reported that HM from mothers with male infants had higher energy content and lipids compared with that mothers of female infants; these differences may be because of differences in nutritional requirements to support specific growth and development patterns between the two sexes [23]. However, in the current study, there were no significant differences in the GA concentrations of either the transitional milk or mature milk breast milk from mothers who had male or female infants. The average TGA levels observed with the UAE cohort were similar to those reported for the Malaysian and Chinese cohorts $(25.3 \pm 15.7 \mathrm{mg} / \mathrm{L}$ and $22.9 \pm 9.9 \mathrm{mg} / \mathrm{L}$, respectively [34,35]), but higher than those 
reported by Thakkar et al. [32] for their Singapore cohort (4.6-5.6 mg/L) and Giuffrida et al. [33] for their Chinese cohort $(11.0 \pm 5.0 \mathrm{mg} / \mathrm{L})$.

Table 5. Human milk mean GM3, GD3, and total ganglioside concentrations reported in the literature for both transitional and mature milk ( $\mathrm{mg} / \mathrm{L} \pm$ standard deviation) ${ }^{\mathrm{a}}$.

\begin{tabular}{cccccc}
\hline Reference & Milk & $n$ & GM3 & GD3 & Total GA \\
\hline Giuffrida et al. [40] China & Colostrum/Transition (0-11 days) & 450 & $3.8 \pm 0.4(47)$ & $4.3 \pm 0.9(53)$ & 8.1 \\
Ma et al. [34] Malaysia & Transition & 12 & $8.3 \pm 4.8(44)$ & $10.6 \pm 4.3(56)$ & $18.9 \pm 6.6$ \\
This Study UAE & Transition (5-15 days) & 41 & $9.5 \pm 8.4(45)$ & $11.7 \pm 9.5(55)$ & $21.2 \pm 11.5$ \\
Ma et al. [34] Malaysia & Mature (6 months) & 42 & $21.4 \pm 13(85)$ & $4.3 \pm 5.5(15)$ & $25.3 \pm 15.7$ \\
Ma et al. [35] China & Mature (6 months) & 20 & $21.4 \pm 9.5(93)$ & $1.5 \pm 1.4(7)$ & $22.9 \pm 9.9$ \\
This Study UAE & Mature (6 Months) & 40 & $18.6 \pm 9.7(92)$ & $1.6 \pm 2.2(8)$ & $20.2 \pm 9.8$ \\
\hline
\end{tabular}

\section{Conclusions}

This study provides new information about the HMO, PL, and GA concentrations in breast milk specific to UAE mothers. Despite reports indicating that human milk composition varies across different geographies and ethnicities, the average HMO, PL, and GA concentrations measured in the MISC study from UAE were within the typical ranges reported for other ethnic cohorts, especially data obtained by the same methodologies. There appear to be more similarities than differences for HMOs, PLs, and GAs in HM from different geographical locations and ethnicities. The similarity in the range of concentrations of HMO, PL, and GA between different cohorts suggests they each have specific biological and functional roles linked to timing of lactation.

Author Contributions: Study conceptualisation, B.Y.F., H.R., H.J.J.M., A.K.H.M., and P.M.; methodology, H.R., H.J.J.M., B.Y.F., and L.M.; formal analysis, B.Y.F., A.K.H.M., L.M., and P.M.; sample collection and selection investigation, M.H., H.R., F.N., H.H., H.J.J.N., R.S.O., and H.A.G.; resources and data curation M.H., H.R., F.N., H.H., H.J.J.M., R.S.O., and H.A.G.; writing—original draft preparation, B.Y.F., A.K.H.M., and P.M.; writing一review and editing, P.M., A.K.H.M., B.Y.F., L.M., H.H., and H.R.; visualisation, H.H., F.N., and R.S.O.; supervision, H.R. and M.H.; project administration, B.Y.F., H.R., and P.M.; funding acquisition, H.R.

Funding: We would like to note that the MISC research study has received funding from Al Jalila Foundation (AJF 201510) and University of Sharjah Collaborative Grant (1501057003-P). The analysis of the samples was supported by the New Zealand Primary Growth Partnership post-farm gate dairy programme, funded by Fonterra Co-operative Group and the New Zealand Ministry for Primary Industries.

Acknowledgments: The authors would like to acknowledge all the mothers who kindly supplied milk samples for this study, Tim Coolbear (Fonterra) for reviewing and editing, and Angela Rowan (Fonterra) for support and guidance for this project.

Conflicts of Interest: P.M., L.M., A.K.H.M., and B.Y.F. are employees of Fonterra Co-operative Group Limited, a company that manufactures infant formula and ingredients used for infant formula manufacture. Other authors declare no conflict of interest.

\section{References}

1. Michaelsen, K.F.; Skafte, L.; Badsberg, J.H.; Jorgensen, M. Variation in Macronutrients in Human bank milk-influencing factors and implications for human-milk banking. J. Pediatr. Gastroenterol. Nutr. 1990, 11, 229-239. [CrossRef] [PubMed]

2. Kunz, C.; Rudloff, S.; Baier, W.; Klein, N.; Strobel, S. Oligosaccharides in human milk: Structural, functional, and metabolic aspects. Annu. Rev. Nutr. 2000, 20, 699-722. [CrossRef] [PubMed]

3. Newburg, D.S.; Neubauer, S.H. Carbohydrates in milk: Analysis, quantities, and Significance. In Handbook of Milk Composition; Jensen, R.G., Ed.; Academic Press: London, UK, 1995; pp. 273-349.

4. Gopal, P.K.; Gill, H.S. Oligosaccharides and glycoconjugates in bovine milk and colostrum. Br. J. Nutr. 2000, 84 (Suppl. S81), S69-S74. [CrossRef]

5. Bode, L. Human milk oligosaccharides: Every baby needs a sugar mama. Glycobiology 2012, 22, 1147-1162. [CrossRef] [PubMed] 
6. Bode, L. The functional biology of human milk oligosaccharides. Early Hum. Dev. 2015, 91, 619-622. [CrossRef] [PubMed]

7. Lin, A.E.; Autran, C.A.; Szyszka, A.; Escajadillo, T.; Huang, M.; Godula, K.; Prudden, A.R.; Boons, G.J.; Lewis, A.L.; Doran, K.S.; et al. Human milk oligosaccharides inhibit growth of group B Streptococcus. J. Biol. Chem. 2017, 292, 11243-11249. [CrossRef]

8. Yu, H.; Lau, K.; Thon, V.; Autran, C.A.; Jantscher-Krenn, E.; Xue, M.; Li, Y.; Sugiarto, G.; Qu, J.; Mu, S.; et al. Synthetic disialyl hexasaccharides protect neonatal rats from necrotizing enterocolitis. Angew. Chem. Int. Ed. Engl. 2014, 53, 6687-6691. [CrossRef]

9. Yu, H.; Yan, X.; Autran, C.A.; Li, Y.; Etzold, S.; Latasiewicz, J.; Robertson, B.M.; Li, J.; Bode, L.; Chen, X. Enzymatic and Chemoenzymatic Syntheses of Disialyl Glycans and Their Necrotizing Enterocolitis Preventing Effects. J. Org. Chem. 2017, 82, 13152-13160. [CrossRef]

10. Ackerman, D.L.; Craft, K.M.; Doster, R.S.; Weitkamp, J.H.; Aronoff, D.M.; Gaddy, J.A.; Townsend, S.D. Antimicrobial and Antibiofilm Activity of Human Milk Oligosaccharides against Streptococcus agalactiae, Staphylococcus aureus, and Acinetobacter baumannii. ACS Infect. Dis. 2018, 4, 315-324. [CrossRef]

11. Ackerman, D.L.; Doster, R.S.; Weitkamp, J.H.; Aronoff, D.M.; Gaddy, J.A.; Townsend, S.D. Human Milk Oligosaccharides Exhibit Antimicrobial and Antibiofilm Properties against Group B Streptococcus. ACS Infect. Dis. 2017, 3, 595-605. [CrossRef]

12. Craft, K.M.; Thomas, H.C.; Townsend, S.D. Interrogation of Human Milk Oligosaccharide Fucosylation Patterns for Antimicrobial and Antibiofilm Trends in Group B Streptococcus. ACS Infect. Dis. 2018, 4, 1755-1765. [CrossRef] [PubMed]

13. Craft, K.M.; Thomas, H.C.; Townsend, S.D. Sialylated variants of lacto-N-tetraose exhibit antimicrobial activity against Group B Streptococcus. Org. Biomol. Chem. 2019, 17, 1893-1900. [CrossRef] [PubMed]

14. Kunz, C. Complex oligosaccharides in infant nutrition. Mon. Kinderheilkd. 1998, 146, S49-S56. [CrossRef]

15. Kunz, C.; Rudloff, S. Biological Functions of Milk Oligosaccharides. Acta Paediatr. 1994, 83, 1042. [CrossRef]

16. Craft, K.M.; Gaddy, J.A.; Townsend, S.D. Human Milk Oligosaccharides (HMOs) Sensitize Group B Streptococcus to Clindamycin, Erythromycin, Gentamicin, and Minocycline on a Strain Specific Basis. ACS Chem. Biol. 2018, 13, 2020-2026. [CrossRef] [PubMed]

17. Urashima, T.; Kitaoka, M.; Terabayashi, T.; Fukuda, K.; Ohnishi, M.; Kobata, A. Milk Oligosaccharides. In Oligosaccharides: Sources, Properties and Application; Gordon, N.S., Ed.; Nova Science Publishers, Inc.: New York, NY, USA, 2011; pp. 1-58.

18. Tonon, K.; de Morais, M.; Abrao, A.; Miranda, A.; Morais, T. Maternal and Infant Factors Associated with Human Milk Oligosaccharides Concentrations According to Secretor and Lewis Phenotypes. Nutrients 2019, 11, 1358. [CrossRef]

19. Mozzi, R.; Buratta, S. Brain Phosphatidylserine: Metabolism and Functions. In Handbook of Neurochemistry and Molecular Neurobiology; Lajtha, A., Tettamanti, G., Goracci, G., Eds.; Springer: Boston, MA, USA, 2010; pp. 39-58. [CrossRef]

20. Contarini, G.; Povolo, M. Phospholipids in Milk Fat: Composition, Biological and Technological Significance, and Analytical Strategies. Int. J. Mol. Sci. 2013, 14, 2808-2831. [CrossRef]

21. Hirabayashi, Y.; Furuya, S. Roles of L-serine and sphingolipid synthesis in brain development and neuronal survival. Prog. Lipid Res. 2008, 47, 188-203. [CrossRef]

22. Küllenberg, D.; Taylor, L.A.; Schneider, M.; Massing, U. Health effects of dietary phospholipids. Lipids Health Dis. 2012, 11. [CrossRef]

23. Farrell, P.M. The development biochemistry of lung phospholipid metabolism. In Lung Development: Biological and Clinical Perspectives: Biochemistry and Physiology; Farrell, P.M., Ed.; Academic Press: Cambridge, MA, USA, 1982; Volume 1, pp. 223-235.

24. McJarrow, P.; Schnell, N.; Jumpsen, J.; Clandinin, T. Influence of dietary gangliosides on neonatal brain development. Nutr. Rev. 2009, 67, 451-463. [CrossRef]

25. Rueda, R. Gangliosides, immunity, infection and inflammation. In Diet, Immunity and Inflammation; Calder, P.C., Yaqoob, P., Eds.; Woodhead Publishing Ltd.: Cambridge, UK, 2013.

26. Sonnino, S.; Mauri, L.; Ciampa, M.G.; Prinetti, A. Gangliosides as regulators of cell signaling: Ganglioside-protein interactions or ganglioside-driven membrane organization? J. Neurochem. 2013, 124, 432-435. [CrossRef] [PubMed] 
27. Thurl, S.; Munzert, M.; Henker, J.; Boehm, G.; Muller-Werner, B.; Jelinek, J.; Stahl, B. Variation of human milk oligosaccharides in relation to milk groups and lactational periods. Br. J. Nutr. 2010, 104, 1261-1271. [CrossRef] [PubMed]

28. McGuire, M.K.; Meehan, C.L.; McGuire, M.A.; Williams, J.E.; Foster, J.; Sellen, D.W.; Kamau-Mbuthia, E.W.; Kamundia, E.W.; Mbugua, S.; Moore, S.E.; et al. What's normal? Oligosaccharide concentrations and profiles in milk produced by healthy women vary geographically. Am. J. Clin. Nutr. 2017, 105, 1086-1100. [CrossRef] [PubMed]

29. Austin, S.; De Castro, C.A.; Benet, T.; Hou, Y.F.; Sun, H.N.; Thakkar, S.K.; Vinyes-Pares, G.; Zhang, Y.M.; Wang, P.Y. Temporal Change of the Content of 10 Oligosaccharides in the Milk of Chinese Urban Mothers. Nutrients 2016, 8, 346. [CrossRef] [PubMed]

30. Ma, L.; McJarrow, P.; Mohamed, H.; Liu, X.Y.; Welman, A.; Fong, B.Y. Lactational changes in the human milk oligosaccharide concentration in Chinese and Malaysian mothers' milk. Int. Dairy J. 2018, 87, 1-10. [CrossRef]

31. Ma, L.; MacGibbon, A.K.H.; Jan Mohamed, H.J.B.; Loy, S.; Rowan, A.; McJarrow, P.; Fong, B.Y. Determination of phospholipid concentrations in breast milk and serum using a high performance liquid chromatography-mass spectrometry-multiple reaction monitoring method. Int. Dairy J. 2017, 71, 50-59. [CrossRef]

32. Thakkar, S.K.; Giuffrida, F.; Cristina, C.-H.; De Castro, C.A.; Mukherjee, R.; Tran, L.-A.; Steenhout, P.; Lee, L.Y.; Destaillats, F. Dynamics of human milk nutrient composition of women from Singapore with a special focus on lipids. Am. J. Hum. Biol. Off. J. Hum. Biol. Counc. 2013, 25, 770-779. [CrossRef]

33. Giuffrida, F.; Cruz-Hernandez, C.; Bertschy, E.; Fontannaz, P.; Elmelegy, I.M.; Tavazzi, I.; Marmet, C.; Sanchez-Bridge, B.; Thakkar, S.K.; De Castro, C.A.; et al. Temporal changes of human breast milk lipids of Chinese mothers. Nutrients 2016, 8, 715. [CrossRef]

34. Ma, L.; MacGibbon, A.K.H.; Jan Mohamed, H.J.B.; Loy, S.; Rowan, A.; McJarrow, P.; Fong, B.Y. Determination of ganglioside concentrations in breast milk and serum from Malaysian mothers using a high performance liquid chromatography-mass spectrometry-multiple reaction monitoring method. Int. Dairy J. 2015, 49, 62-71. [CrossRef]

35. Ma, L.; Liu, X.; MacGibbon, A.K.H.; Rowan, A.; McJarrow, P.; Fong, B.Y. Lactational changes in concentration and distribution of ganglioside molecular species in human breast milk from Chinese mothers. Lipids 2015, 50, 1145-1154. [CrossRef]

36. Radwan, H.; Hashim, M.; Obaid, R.S.; Hasan, H.; Naja, F.; Al Ghazal, H.; Mohamed, H.; Rizk, R.; Al Hilali, M.; Rayess, R.; et al. The Molther-Infant Study Cohort (MISC): Methodology, challenges, and baseline characteristics. PLoS ONE 2018, 13, e0198278. [CrossRef] [PubMed]

37. Svennerholm, L.; Fredman, P. A procedure for the quantitative isolation of brain gangliosides. Biochim. Biophys. Acta 1980, 617, 97-109. [CrossRef]

38. Fong, B.; Ma, L.; Norris, C. Analysis of phospholipids in infant formulas using high performance liquid chromatography-tandem mass spectrometry. J. Agric. Food Chem. 2013, 61, 858-865. [CrossRef] [PubMed]

39. Azad, M.B.; Robertson, B.; Atakora, F.; Becker, A.B.; Subbarao, P.; Moraes, T.J.; Mandhane, P.J.; Turvey, S.E.; Lefebvre, D.L.; Sears, M.R.; et al. Human milk oligosaccharide concentrations are associated with multiple fixed and modifiable maternal characteristics, environmental factors, and feeding practices. J. Nutr. 2018, 148, 1733-1742. [CrossRef] [PubMed]

40. Giuffrida, F.; Elmelegy, I.M.; Thakkar, S.K.; Marmet, C.; Destaillats, F. Longitudinal Evolution of the Concentration of Gangliosides GM3 and GD3 in Human Milk. Lipids 2014, 49, 997-1004. [CrossRef] [PubMed]

41. Larsson, M.W.; Lind, M.V.; Laursen, R.P.; Yonemitsu, C.; Larnkjaer, A.; Molgaard, C.; Michaelsen, K.F.; Bode, L. Human Milk Oligosaccharide Composition Is Associated with Excessive Weight Gain During Exclusive Breastfeeding-An Explorative Study. Front. Pediatr. 2019, 7, 297. [CrossRef] [PubMed]

42. Coppa, G.V.; Pierani, P.; Zampini, L.; Carloni, I.; Carlucci, A.; Gabrielli, O. Oligosaccharides in human milk during different phases of lactation. Acta Paediatr. Suppl. 1999, 88, 89-94. [CrossRef] [PubMed]

43. Bao, Y.W.; Zhu, L.B.; Newburg, D.S. Simultaneous quantification of sialyloligosaccharides from human milk by capillary electrophoresis. Anal. Biochem. 2007, 370, 206-214. [CrossRef] [PubMed]

44. Hong, Q.T.; Ruhaak, L.R.; Totten, S.M.; Smilowitz, J.T.; German, J.B.; Lebrilla, C.B. Label-Free Absolute Quantitation of Oligosaccharides Using Multiple Reaction Monitoring. Anal. Chem. 2014, 86, 2640-2647. [CrossRef] [PubMed] 
45. Garcia, C.; Millet, V.; Coste, T.C.; Mimoun, M.; Ridet, A.; Antona, C.; Simeoni, U.; Armand, M. French Mothers' Milk Deficient in DHA Contains Phospholipid Species of Potential Interest for Infant Development. J. Pediatr. Gastroenterol. Nutr. 2011, 53, 206-212. [CrossRef] [PubMed]

46. Claumarchirant, L.; Cilla, A.; Matencio, E.; Sanchez-Siles, L.M.; Castro-Gomez, P.; Fontecha, J.; Alegria, A.; Lagarda, M.J. Addition of milk fat globule membrane as an ingredient of infant formulas for resembling the polar lipids of human milk. Int. Dairy J. 2016, 61, 228-238. [CrossRef]

47. Bitman, J.; Freed, L.M.; Neville, M.C.; Wood, D.L.; Hamosh, P.; Hamosh, M. Lipid-composition of prepartum human mammary secretion and postpartum milk. J. Pediatr. Gastroenterol. Nutr. 1986, 5, 608-615. [CrossRef] [PubMed]

48. Sala-Vila, A.; Castellote, A.I.; Rodriguez-Palmero, M.; Campoy, C.; Lopez-Sabater, M.C. Lipid composition in human breast milk from Granada (Spain): Changes during lactation. Nutrition 2005, 21, 467-473. [CrossRef] [PubMed]

49. Bitman, J.; Wood, L.; Hamosh, M.; Hamosh, P.; Mehta, N.R. Comparison of the lipid composition of breast milk from mothers of term and preterm infants. Am. J. Clin. Nutr. 1983, 38, 300-312. [CrossRef]

50. Clark, R.M.; Ferris, A.M.; Fey, M.; Brown, P.B.; Hundrieser, K.E.; Jensen, R.G. Changes in the lipids of human milk from 2 to 16 weeks postpartum. J. Pediatr. Gastroenterol. Nutr. 1982, 1, 311-315. [CrossRef]

51. Zou, X.Q.; Guo, Z.; Huang, J.H.; Jin, Q.Z.; Cheong, L.Z.; Wang, X.G.; Xu, X.B. Human Milk Fat Globules from Different Stages of Lactation: A Lipid Composition Analysis and Microstructure Characterization. J. Agric. Food Chem. 2012, 60, 7158-7167. [CrossRef]

52. Harzer, G.; Haug, M.; Dieterich, I.; Gentner, P.R. Changing patterns of human milk lipids in the course of the lactation and during the day. Am. J. Clin. Nutr. 1983, 37, 612-621. [CrossRef]

53. Jensen, R.G. F-Miscellaneous Factors Affecting Composition and Volume of Human and Bovine Milks. In Handbook of Milk Composition; Jensen, R.G., Ed.; Academic Press: San Diego, CA, USA, 1995; pp. $237-271$. [CrossRef]

54. Da Cunha, J.; da Costa, T.H.M.; Ito, M.K. Influences of maternal dietary intake and suckling on breast milk lipid and fatty acid composition in low-income women from Brasilia, Brazil. Early Hum. Dev. 2005, 81, 303-311. [CrossRef]

55. Jensen, R.G. Lipids in human milk. Lipids 1999, 34, 1243-1271. [CrossRef]

56. Jensen, R.G. Handbook of Milk Composition; Academic Press: London, UK, 1995.

57. Michalski, M.C.; Briard, V.; Michel, F.; Tasson, F.; Poulain, P. Size distribution of fat globules in human colostrum, breast milk, and infant formula. J. Dairy Sci. 2005, 88, 1927-1940. [CrossRef]

58. Cohen, B.C.; Shamay, A.; Argov-Argaman, N. Regulation of Lipid Droplet Size in Mammary Epithelial Cells by Remodeling of Membrane Lipid Composition-A Potential Mechanism. PLoS ONE 2015, 10. [CrossRef] [PubMed]

59. Takamizawa, K.; Iwamori, M.; Mutai, M.; Nagai, Y. Gangliosides of Bovine Buttermilk-Isolation and Characterization of a Novel Monosialoganglioside with a New Branching Structure. J. Biol. Chem. 1986, 261, 5625-5630.

60. Nakano, T.; Sugawara, M.; Kawakami, H. Sialic acid in human milk: Composition and functions. Acta Paediatr. Taiwanica 2001, 42, 11-17.

61. Rueda, R.; Puente, R.; Hueso, P.; Maldonado, J.; Gil, A. New data on content and distribution of gangliosides in human milk. Biol. Chem. Hoppe-Seyler 1995, 376, 723-727. [CrossRef] [PubMed]

62. Pan, X.L.; Izumi, T. Chronological changes in the ganglioside composition of human milk during lactation. Early Hum. Dev. 1999, 55, 1-8. [CrossRef]

(C) 2019 by the authors. Licensee MDPI, Basel, Switzerland. This article is an open access article distributed under the terms and conditions of the Creative Commons Attribution (CC BY) license (http://creativecommons.org/licenses/by/4.0/). 